\title{
ELEMENTO SUBJETIVO DO CRIME DE LAVAGEM DE DINHEIRO NO ÂMBITO FINANCEIRO
}

\author{
Dissertação de mestrado \\ Orientadora: Professora Associada Ana Elisa Liberatore Silva Bechara
}

Universidade de São Paulo

Faculdade de Direito

São Paulo/SP

2017 


\title{
ELEMENTO SUBJETIVO DO CRIME DE LAVAGEM DE DINHEIRO NO ÂMBITO FINANCEIRO
}

\begin{abstract}
Dissertação apresentada à Banca Examinadora do Programa de Pósgraduação em Direito, da Faculdade de Direito da Universidade de São Paulo, como exigência parcial para obtenção do Título de Mestre em Direito, na área de concentração Direito Penal, Medicina Forense e Criminologia, sob orientação da Professora Associada Ana Elisa Liberatore Silva Bechara.
\end{abstract}

Universidade de São Paulo

Faculdade de Direito

São Paulo/SP 
Autorizo a reprodução e divulgação total ou parcial deste trabalho, por qualquer meio convencional ou eletrônico, para fins de estudo e pesquisa, desde que citada a fonte.

Catalogação da Publicação

Serviço de Biblioteca e Documentação

Faculdade de Direito da Universidade de São Paulo

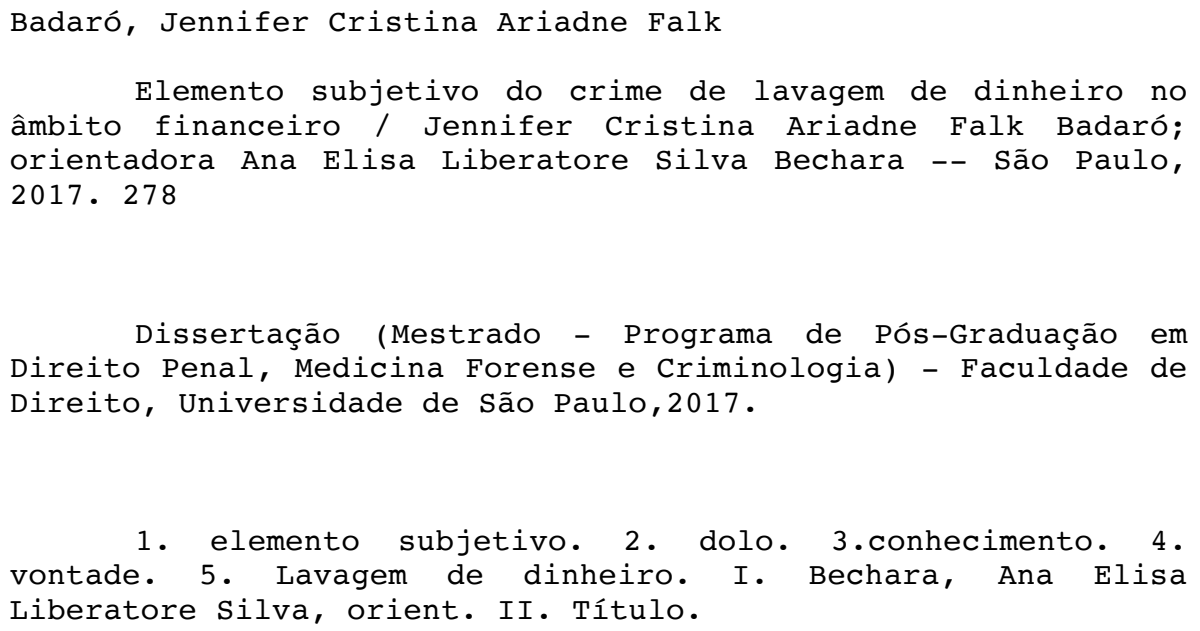

1. elemento subjetivo. 2. dolo. 3.conhecimento. 4 . vontade. 5. Lavagem de dinheiro. I. Bechara, Ana Elisa Liberatore Silva, orient. II. Título. 


\section{ELEMENTO SUBJETIVO DO CRIME DE LAVAGEM DE DINHEIRO NO ÂMBITO FINANCEIRO}

Dissertação apresentada à Banca Examinadora do Programa de Pós-graduação em Direito, da Faculdade de Direito da Universidade de São Paulo, como exigência parcial para obtenção do Título de Mestre em Direito, na área de concentração Direito Penal, Medicina Forense e Criminologia, sob orientação da Professora Associada Ana Elisa Liberatore Silva Bechara.

BANCA EXAMINADORA

Presidente:

Professora Associada Ana Elisa Liberatore Silva Bechara

$1^{\circ}$ Examinador (a):

$2^{\circ}$ Examinador (a): 
Para Enrico, pelo amor incondicional. 


\section{AGRADECIMENTOS}

À Professora Ana Elisa Liberatore Silva Bechara, por ter confiado em meu projeto e por todo o aprendizado nesses anos de pesquisa.

Aos Professores Helena Regina Lobo da Costa e Alamiro Velludo Salvador Netto, pelas valiosas e estimulantes contribuições no Exame de Qualificação.

Ao Professor Renato de Mello Jorge Silveira, pelo incentivo nos meus estudos, pela oportunidade que me concedeu para pesquisar na Universidade Pompeu Fabra, pelo diálogo constante e por todos os ensinamentos.

Ao meu marido Gustavo Badaró, que me apoiou desde o início desta empreitada, pela companhia durante todos esses anos de pesquisa, pelas trocas de ideias, pela correção do trabalho. E, especialmente, pelo amor, pelo carinho e por estar sempre ao meu lado.

Às amigas Silvana Monteiro da Silva e Bruna Gonçalves, pela amizade e pela companhia ao longo dessa jornada.

Ao meu filho Enrico, pela compreensão. 
BADARÓ, Jennifer Cristina Ariadne Falk. Elemento subjetivo no crime de lavagem de dinheiro no âmbito financeiro. 2017. 278p. Mestrado - Faculdade de Direito. Universidade de São Paulo, São Paulo, 2017.

\section{RESUMO}

O trabalho analisa o elemento subjetivo no crime de lavagem de dinheiro no ordenamento jurídico brasileiro. A primeira parte consistiu no levantamento bibliográfico, da doutrina nacional e estrangeira, sobre as diversas teorias sobre o dolo. Adotou-se o posicionamento de que o dolo é o conhecimento da alta probabilidade de que a conduta irá causar o resultado típico, o qual deverá ser constatado a partir de critérios objetivos, considerando o conhecimento de qualquer pessoa que pensa e age racionalmente. Tal posição é compatível com o ordenamento jurídico brasileiro. $\mathrm{Na}$ segunda parte, foi analisado o dolo nas diversas modalidades de lavagem de dinheiro no ordenamento jurídico brasileiro. Na figura principal da lavagem de dinheiro, do caput do artigo $1^{\circ}$ da Lei 9.613/98, concluiu serem necessários três elementos para a configuração do dolo: o conhecimento, com alto grau de probabilidade, de que aquele bem, direito ou valor, seja de origem ilícita; o conhecimento de que há uma alta probabilidade de que, com aquela conduta, está-se ocultando ou dissimulando um dos atributos previstos no tipo penal quanto ao bem, direito ou valor; adicionalmente, o conhecimento de que, muito provavelmente, aquela conduta se insere em um esquema de lavagem de dinheiro, de forma que aquela ocultação ou dissimulação é apenas parte de um processo, cujo objetivo é reinserir tal bem na economia com a aparência lícita.

Palavras-chave: elemento subjetivo - dolo - conhecimento - vontade - lavagem de dinheiro. 
BADARÓ, Jennifer Cristina Ariadne Falk. Elemento subjetivo no crime de lavagem de dinheiro no âmbito financeiro. 2017. 278p. Mestrado - Faculdade de Direito. Universidade de São Paulo, São Paulo, 2017.

\begin{abstract}
The paper analyzes the subjective element in the crime of money laundering in the Brazilian legal system. The first part is consisted of a bibliographical survey of national and foreign doctrine on the various theories of deceit. It was adopted the position that the deceit is the knowledge of the high probability that the conduct will cause the typical result, which should be verified from objective criteria, considering the knowledge of any person who thinks and acts rationally. Such a position is compatible with the Brazilian legal system. In the second part, the intent was analyzed in the various modalities of money laundering in the Brazilian legal system. In the main figure of money laundering, from the caput of article 1 of Law 9.613/98, the conclusion is that three elements are necessary for the configuration of deceit: knowledge, with a high degree of probability, that that good, right or value, is of illicit origin; the knowledge that there is a high probability that, with that conduct, one is hiding or concealing one of the attributes provided in the criminal type as to the good, right or value; in addition, the knowledge that such conduct is most likely to be part of a money laundering scheme, so that hiding or concealment is only part of a process, the purpose of which is to reinsert such good in the economy with a lawful appearance.
\end{abstract}

Key-words: subjective element - deceit - knowledge - intention - money laundering. 


\section{SUMÁRIO}

INTRODUÇÃO 12

PARTE I - TEORIAS DO DOLO .16

CAPÍTULO 1 - TEORIAS CLÁSSICA DO DOLO .................................................16

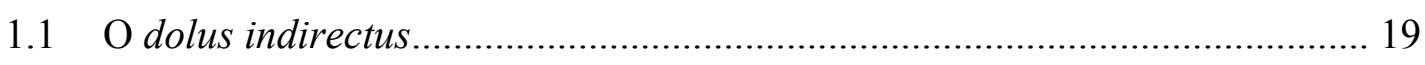

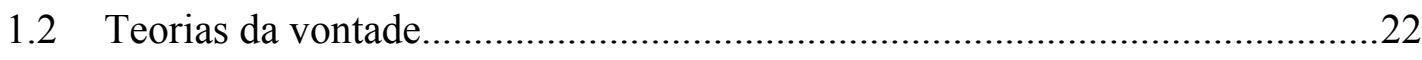

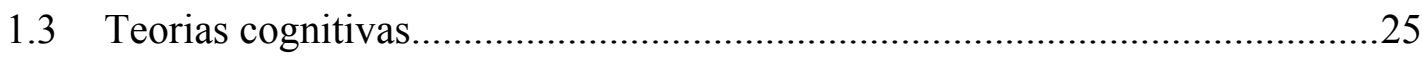

1.3.1 Teoria da representação......................................................................... 25

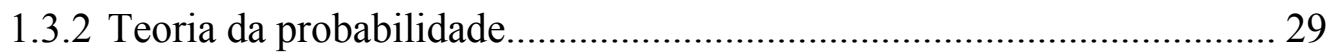

1.3.3 Teoria da possibilidade......................................................................... 33

CAPÍTULO 2 - TEORIAS ATUAIS DO DOLO……………………………...... 35

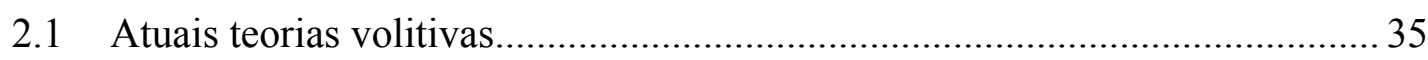

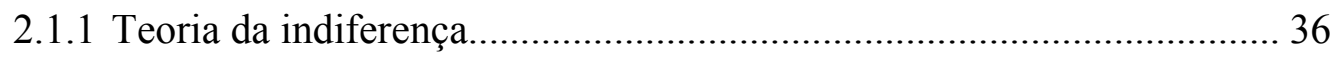

2.1.2 Teoria do consentimento ou aprovação................................................... 39

2.1.3 Teoria da evitação................................................................................... 41

2.1.4 Teoria de levar a sério o perigo............................................................4

2.1.5 Teoria da decisão contrária ao bem jurídico............................................. 47

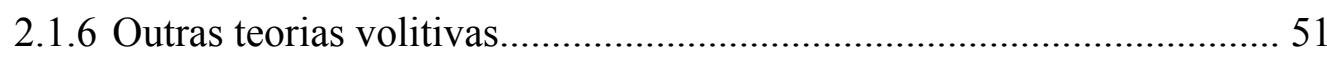

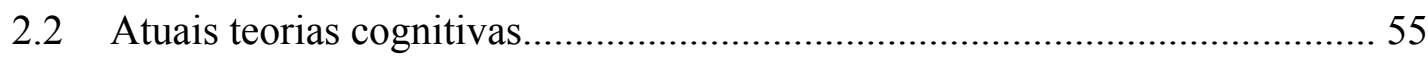

2.2.1 Teorias da probabilidade................................................................... 56

2.2.1.1 A teoria de Ingeborg Puppe........................................................ 58

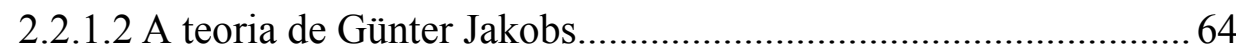

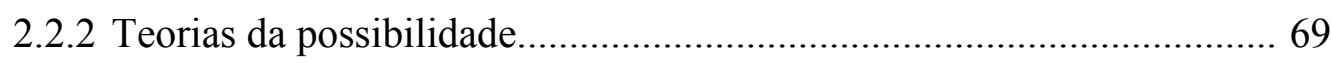

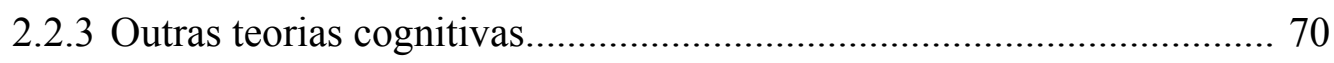

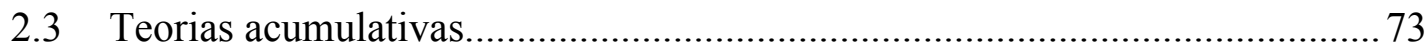

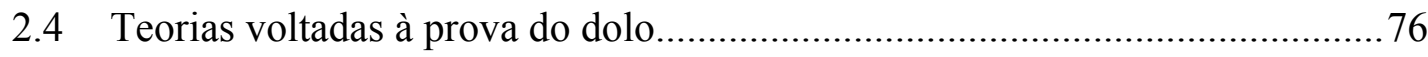

2.5 A teoria de Gabriel Pérez Barberá...................................................................... 86

2.6 Recklessness.................................................................................. 96

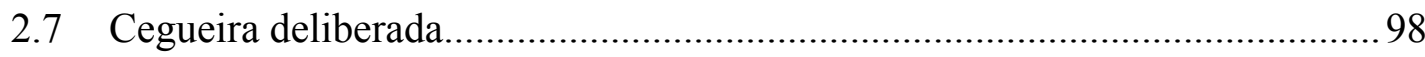


3.1 Evolução do tratamento jurídico-penal do dolo no Brasil.................................104

3.1.1 Dos antecedentes legais do Código Penal de 1940........................... 104

3.1.2 O dolo no Código Penal de 1940................................................. 109

3.1.3 O dolo na Reforma da Parte Geral de 1984..................................... 111

3.1.4 O dolo no Projeto de Código Penal - PLS 236/2012 _...................... 118

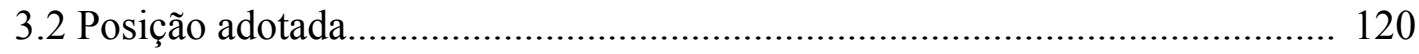

3.3 Análise da compatibilidade de uma teoria cognitiva do dolo com o Direito Penal Brasileiro.

\section{PARTE II - O ELEMENTO SUBJETIVO NA LAVAGEM DE DINHEIRO NO DIREITO PENAL BRASILEIRO.}

\section{CAPÍTULO 4 - O CRIME DE LAVAGEM DE DINHEIRO .............................130}

4.1 Conceito e importância do controle da lavagem de dinheiro.......................... 131

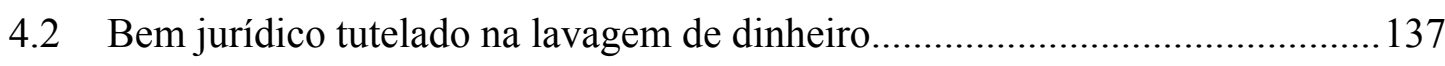

4.2.1 A proteção subsidiária a bens jurídicos................................................137

4.2.2 O bem jurídico tutelado na lavagem de dinheiro.................................. 140

4.3 Evolução do tratamento jurídico-penal da lavagem de dinheiro no Brasil...... 144

4.4 Política criminal de controle da lavagem de dinheiro e a imposição de deveres de vigilância no âmbito financeiro bancário: o estabelecimento de um modelo penal preventivo

4.4.1 Deveres no controle da lavagem de dinheiro no sistema financeiro bancário 156

4.4.1.1 Dever de identificação dos clientes e de manutenção dos registros das transações financeiras. 157

4.4.1.2 Dever de comunicação de operações financeiras suspeitas... 163 4.4.2 Consequências jurídico-administrativas da violação dos deveres de vigilância no combate à lavagem de dinheiro. 169

4.5 Análise quanto à possibilidade de responsabilização penal pela prática de lavagem de dinheiro por omissão imprópria, a partir do descumprimento dos deveres administrativos impostos pela Lei 9.613/98, no âmbito financeiro bancário 171 
4.5.1.1 Distinção entre crimes omissivos próprios e crimes omissivos

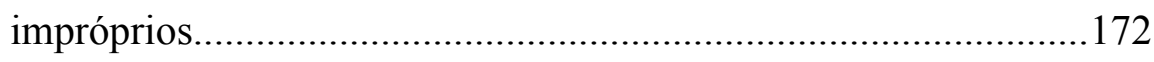

4.5.1.2 Os elementos do tipo nos crimes omissivos impróprios....... 173

4.5.2 Análise crítica quanto à responsabilidade penal pelo descumprimento dos deveres de vigilância referentes à lavagem de dinheiro. 182

4.5.3 Da delegação da posição de garantidor nas instituições financeiras bancárias e a responsabilização criminal por lavagem de dinheiro 191

\section{CAPÍTULO 5 - O ELEMENTO SUBJETIVO NA LAVAGEM DE DINHEIRO NO ÂMBITO FINANCEIRO BANCÁRIO.......................................... 197}

5.1 Crítica quanto a uma visão tradicional do dolo na lavagem de dinheiro.......... 198

5.2 Proposta para a tipicidade subjetiva na lavagem de dinheiro na Lei 9.613/98...203

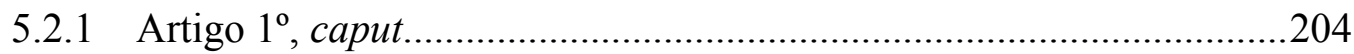

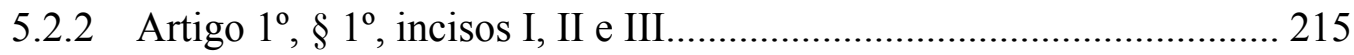

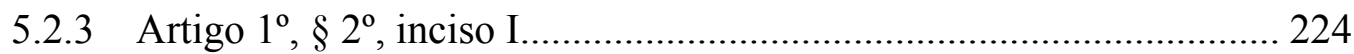

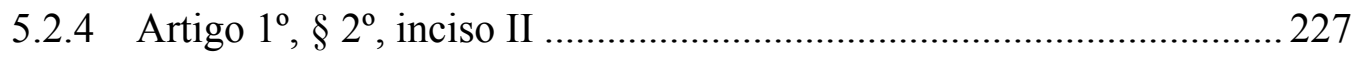

5.2.5 Dolo e os operadores financeiros bancários..................................... 230

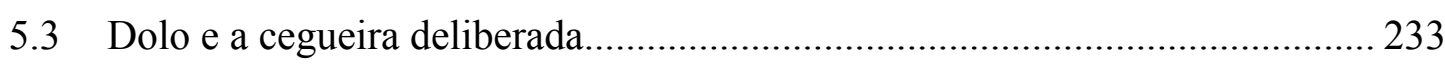

5.4 A possibilidade de tipificação da conduta culposa da lavagem de dinheiro.... 238

5.4.1 A tipificação da conduta culposa da lavagem de dinheiro.................... 239

5.4.2 A culpa e os sujeitos obrigados.......................................................... 243

5.4.3 Críticas à possibilidade de tipificação da modalidade culposa do crime de lavagem de dinheiro no Brasil............................................................ 247

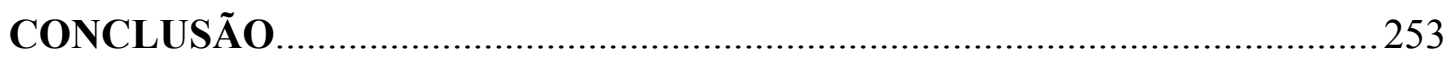

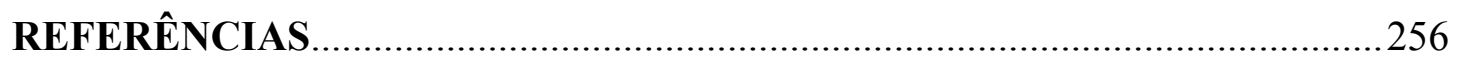




\section{INTRODUÇÃO}

O Código Penal brasileiro definiu duas espécies de dolo, uma como sendo o querer o resultado, e outra como assumir o risco de sua produção. Provavelmente influenciada por essa tomada de posição legislativa, não há uma movimentação significativa da doutrina nacional no sentido de questionar o conteúdo do dolo e nem de verificar se a disposição legal atende as necessidades dos casos concretos.

Em sua grande maioria, a doutrina nacional considera que o dolo é composto por um elemento cognitivo, que é o conhecimento, e por um elemento volitivo, que é a vontade. $\mathrm{O}$ que se encontra na doutrina são discussões sobre como delimitar o dolo eventual da culpa consciente.

Contudo, verifica-se que a forma como o dolo tem sido tratado, a partir de sua definição legal, não soluciona, de modo adequado e satisfatório, os problemas que hoje tem de ser enfrentados, especialmente, quando se está diante de crimes econômicos, praticados no âmbito de instituições financeiras bancárias, como é o caso do delito de lavagem de dinheiro.

Os dirigentes de instituições financeiras e, em especial, os agentes bancários, estão muito expostos à utilização, em sua atividade normal, de valores que sejam produto de crimes, realizando com eles operações bancárias que podem ser, em tese, consideradas caracterizadoras de uma ou mais etapas de lavagem de dinheiro. Ainda que se conclua que, do ponto de vista objetivo, tais condutas são típicas, se subsumindo a uma das figuras de lavagem de dinheiro previstas na Lei 9.613/98, resta o problema de definir se, subjetivamente, se está diante de um agir doloso do agente. Em outras palavras, há uma grande dificuldade em identificar a presença do elemento subjetivo no crime de lavagem de dinheiro.

Em razão dos problemas decorrentes do emprego dos conceitos de dolo utilizados pelo legislador, bem como da dificuldade probatória do dolo, tanto em relação ao conhecimento quanto em relação ao elemento psicológico, mais recentemente tem se verificado uma ampliação do emprego do dolo eventual pelos tribunais e doutrina nacionais, tendo por consequência que sejam consideradas dolosas condutas que, muitas vezes, seriam melhor definidas como atos meramente culposos. Outras situações que têm levado ao uma hipertrofia das imputações e condenações a título de dolo são, de um 
lado, a importação de teorias estrangeiras, como a da cegueira deliberada, equiparando-a ao dolo eventual, e de outro, a responsabilização criminal decorrente de mero descumprimento de deveres administrativos.

O resultado desse cenário confuso e obscuro tem sido, atualmente, uma total falta de segurança em relação à atribuição de crimes a título de dolo, carecendo o aplicador do direito de parâmetros objetivos para resolver os casos práticos, em especial, os mais complexos.

Um dos caminhos que se pode percorrer para eliminar tais dificuldades é buscar uma definição melhor e mais clara do dolo, com delimitação do seu conteúdo, que terá, por consequência, uma maior segurança jurídica na sua aplicação.

O dolo é elemento da teoria do delito e deve, como tal, ter um conceito uniforme para todas as infrações penais, desde o clássico crime de homicídio até o moderno delito de lavagem de dinheiro. Um conceito de dolo que seja cientificamente correto e operacionalmente útil apenas para parcela dos delitos, ou à maioria dos crimes, não será uma solução satisfatória.

Evidente que não se pretende, numa dissertação de mestrado, desenvolver uma nova teoria sobre o dolo, mormente diante de tudo o que já foi e ainda é discutido na doutrina, especialmente a estrangeira, sobre a tipicidade subjetiva. $\mathrm{O}$ que se pretende fazer nas páginas que seguem, é expor e analisar as principais teorias do dolo já desenvolvidas, a fim de identificar qual delas propõe o melhor conceito de dolo, do ponto dogmático, que ao mesmo tempo seja apta à resolução, com clareza e segurança, dos problemas enfrentados no direito nacional, especialmente em relação ao crime de lavagem de dinheiro.

Para tanto, o presente trabalho será dividido em duas partes, cada uma com três capítulos. O objeto da primeira parte será o estudo das teorias sobre a distinção entre o dolo e a culpa; o objeto da segunda, será o elemento subjetivo no crime de lavagem de dinheiro.

Na primeira parte, o Capítulo 1 tratará das teorias clássicas sobre o dolo e a culpa, traçando um panorama doutrinário desde a construção da figura do dolus indirectus, até as teorias da vontade e as teorias cognitivas desenvolvidas no século XVIII e início do século XIX.

No Capítulo 2 serão expostas as teorias denominadas de "atuais", assim consideradas aquelas desenvolvidas partir de 1930 até os dias atuais. A exposição será 
dividida em: teorias volitivas, as quais consideram necessária a presença de um elemento volitivo no dolo; teorias cognitivas, para as quais é necessário apenas o elemento cognitivo; teorias acumulativas, que consideram na conceituação do dolo tanto elementos das teorias volitivas, quanto das teorias cognitivas; teorias voltadas à prova do dolo, que não se preocupam tanto com o conceito de dolo, mas sim com um significado de dolo que possa ser provado no caso concerto; e, por fim, será dado destaque à teoria desenvolvida por Gabriel Pérez Barberá, que em profundo estudo sobre o tema, propõe uma concepção de dolo diferente de todas as demais teorias. Ainda no segundo Capítulo, também serão tratadas as figuras da recklessless, que é uma modalidade de tipicidade subjetiva do direito norte-americano, bem como da cegueira deliberada, que tem sua origem na willful blindness, também norte-americana, a qual tem sido aceita pela jurisprudência espanhola, e que agora tem tido alguma aceitação nos tribunais pátrios.

No Capítulo 3, será exposto o tratamento do tipo subjetivo no ordenamento jurídico nacional, desde o Código Penal do Império, de 1930, até o atual Código Penal, de 1940, com a reforma da parte geral de 1984. Após a verificação de como o tema foi e é tratado na legislação brasileira, será exposta, do ponto de vista doutrinário, qual a posição adotada quanto às diversas teorias do dolo e, principalmente, se verificará a compatibilidade ou não da posição teórica abraçada com o conceito atual de dolo do artigo 18, caput, inciso I, do Código Penal brasileiro. Com isso, encerra-se a primeira parte do trabalho, adotando-se uma posição teórica sobre o dolo e verificando sua aplicação no direito penal brasileiro.

A segunda parte do trabalho tem como objetivo analisar o elemento subjetivo no crime de lavagem de dinheiro.

No Capítulo 4, será feita uma abordagem sobre a origem, o conceito e a importância do controle de lavagem de dinheiro, bem como sobre o bem jurídico penalmente tutelado em tal crime. Para tanto, faz-se necessária uma exposição da evolução jurídico-penal da lavagem de dinheiro no Brasil. Será objeto de atenção, também, a política criminal de controle e prevenção de lavagem de dinheiro, mediante a imposição de deveres a sujeitos que atuam em setores sensíveis e particularmente suscetíveis a realização de atividades de ocultação e dissimulação de produtos de crime, com atenção especialmente voltada para as instituições financeiras bancárias. Serão verificados quais são esses deveres e quem, dentro da instituição financeira, é o 
responsável administrativamente pelo cumprimento das medidas impostas e pelo seu descumprimento.

Tratará, ainda, da possibilidade do cometimento de lavagem de dinheiro mediante omissão imprópria. Partindo da previsão da relevância penal da omissão, disciplinada no $\S 2^{\circ}$ do artigo 13 do Código Penal, se pretende verificar, basicamente, se os sujeitos obrigados administrativamente, com fim de prevenção do crime de lavagem de dinheiro, e que exercem atividade em instituições financeiras bancárias, podem responder criminalmente pelo crime de lavagem de dinheiro, por omissão imprópria, a partir do descumprimento dos deveres impostos na Lei 9.613/98.

Por fim, no Capítulo 5 serão analisados todos os tipos penais da lavagem de dinheiro previstos na Lei 9.613/98, com a finalidade específica de permitir uma tomada de posição quanto ao elemento subjetivo exigido em cada um dos tipos. Partindo do conceito de dolo adotado no terceiro capítulo, verificar-se-á se a teoria acolhida proporciona uma solução mais satisfatória, para a atual discussão sobre o elemento subjetivo nos tipos penais da Lei 9.613/98, que praticamente tem se limitado ao dissenso sobre o cabimento ou não do dolo eventual, e sobre a necessidade ou não de que o agente tenha um especial fim de agir. Também será verificada a possibilidade de se equiparar a cegueira deliberada ao dolo, como suscitado por alguns doutrinadores, mormente em sistemas estrangeiros. Por fim, e de lege ferenda, será discutida a possibilidade e, em caso positivo, a conveniência da criação da modalidade culposa da lavagem de dinheiro no ordenamento jurídico nacional. 


\section{CONCLUSÃO}

1. Remonta ao século XIX o início do embate entre os doutrinadores quanto à necessidade ou não do elemento volitivo para a caracterização do dolo, mas a discussão permanece atual.

2. As clássicas teorias volitivas consideravam necessária a vontade apenas para a forma do dolo direito de primeiro grau, enquanto que, para as demais modalidades de dolo, quais sejam, dolo direito de primeiro grau e dolo eventual, não se considera presente o querer, mas formas equiparadas a ele.

3. As teorias cognitivas consideram desnecessário o elemento volitivo para a caracterização do dolo, reputando relevante, apenas, o conhecimento. Divergem quanto ao grau desse conhecimento: se suficiente a possibilidade ou se necessária uma probabilidade de ocorrência do resultado.

4. O conhecimento é o único elemento do dolo que está presente em todas as teorias volitivas e cognitivas. Normalmente, para as teorias volitivas, o grau que se exige do conhecimento é relativamente menor do que para as teorias cognitivas, na medida em que o elemento volitivo suprime a deficiência cognitiva.

5. Nas atuais teorias do dolo, há uma maior preocupação com os limites do dolo e sua distinção com a culpa. Diversas teorias volitivas foram desenvolvidas com a preocupação de estabelecer um critério para distinguir o dolo eventual da culpa consciente, atribuindo a esse critério algum elemento de caráter psicológico.

6. A vontade, por ser algo interno ao agente, não possui um critério seguro para sua constatação, deixando a cargo do subjetivismo do julgador a análise de fatores relacionados ao agente, o que remonta mais a um direito penal do autor, e não do fato.

7. As teorias cognitivas mais modernas consideram desnecessária a presença do elemento volitivo para o dolo. Havendo o conhecimento do agente de que sua conduta poderá causar o resultado, é indiferente a sua intenção ou propósito.

8. As teorias cognitivas divergem quanto ao grau do conhecimento que se exige para considerar presente o dolo. Para alguns, basta a possibilidade de que a conduta do agente causará o resultado, apara outros, é necessária a probabilidade de que tal resultado se verifique. Há, ainda, aqueles que exigem que esta probabilidade seja elevada. 
9. A segunda divergência se refere à forma de constatação desse conhecimento. Há quem considere que deva ser levado em conta o conhecimento do próprio agente, enquanto outros defendem que o dolo deve ser constatado a partir de critérios objetivos. 10. Adota-se a teoria cognitiva proposta por Ingeborg Puppe, segundo a qual o dolo é o conhecimento da alta probabilidade de que a conduta irá causar o resultado típico, o qual deverá ser constatado a partir de critérios objetivos, considerando o conhecimento de qualquer pessoa que pensa e age racionalmente.

11. Uma das consequências da teoria da Puppe é não haver distinção entre dolo direto de primeiro grau, dolo direto de segundo grau e dolo eventual. Haverá um único dolo, para o qual bastará o conhecimento. Qualquer atributo de caráter volitivo estará fora do âmbito de imputação subjetiva.

12. Esta concepção cognitiva sobre o dolo é compatível com o Direito Penal brasileiro, e pode ser considerada para todos os delitos previstos no ordenamento jurídico.

13. A lavagem de dinheiro pode ser compreendida como um processo através do qual bens de origem delitiva passam a integrar o sistema econômico legal, com aparência de lícitos. No Brasil, o legislador tipificou apenas condutas correspondem a algumas das fases da lavagem de dinheiro, não exigindo o término de todo o processo para a configuração do crime. Porém, o objetivo de reintegrar tais bens na economia com aparência de licitude deve estar presente para configurar os tipos penais da lavagem, especialmente em se considerando a ordem socioeconômica como o bem jurídico tutelado.

14. Analisando o elemento subjetivo da conduta principal da lavagem de dinheiro, prevista no caput do artigo $1^{\circ}$ da Lei 9.613/98, são necessários três elementos: o conhecimento, com alto grau de probabilidade, de que aquele bem, direito ou valor, seja de origem ilícita; o conhecimento de que há uma alta probabilidade de que, com aquela conduta, está-se ocultando ou dissimulando um dos atributos previstos no tipo penal quanto ao bem, direito ou valor; adicionalmente, o conhecimento de que, muito provavelmente, aquela conduta se insere em um esquema de lavagem de dinheiro, de forma que aquela ocultação ou dissimulação é apenas parte de um processo, cujo objetivo é reinserir tal bem na economia com a aparência lícita. 
15. No que se refere às instituições financeiras bancárias, que são sujeitos obrigados administrativamente nos termos do artigo $9^{\circ}$ da Lei 9.613/98, para a tipicidade subjetiva, a constatação do conhecimento não deverá como parâmetro o sujeito comum, mas sim daquela categoria de pessoas detentoras de determinados conhecimentos específicos, que mais facilmente podem identificar operações suspeitas de lavagem de dinheiro.

16. É possível a prática do crime de lavagem de dinheiro, por meio de omissão imprópria, uma vez presentes todos os seus elementos. Contudo, os deveres administrativos impostos às instituições financeiras bancárias, nos artigos 10 e 11 da Lei 9.613/98, se descumpridos, não poderão acarretar na imputação do crime de lavagem de dinheiro, a título de omissão imprópria, pois, o resultado típico já terá se verificado antes da inobservância do dever de agir. 


\section{REFERÊNCIAS}

ABEL SOUTO, Miguel. El blanqueo de dinero en la normativa internacional. Especial referencia a los aspectos penales. Santiago de Compostela: Universidad de Santiago de Compostela, 2002.

ABEL SOUTO, Miguel; SÁNCHES STEWART, Nielson. IV Congresso internacional sobre prevención y represión del blanqueo de dinero. Valencia: Tirant lo blanch, 2014.

ALIAGA MÉNDEZ, Juan Antonio. Normativa comentada de prevención del blanqueo de capitales. Adaptada a la Ley 10/2010. Madrid: La Ley, 2010.

ALVES JÚNIOR, Thomaz. Annotações Theoricas e Praticas ao Codigo Criminal. Rio de Janeiro: Francisco Luiz Pinto e C., Tomo I, 1864.

AMBOS, Kai. Lavagem de dinheiro e direito penal. Trad. Pablo Rodrigo Alflen da Silva. Porto Alegre: Sergio Antonio Fabris, 2007.

ARANGUEZ SÁNCHEZ, Carlos. EI delito de blanqueo de capitales. Madrid: Marcial Pons, 2000.

BACIGALUPO, Enrique. Compliance y derecho penal. Cizur Menor: Aranzdi, 2011. Derecho penal. Parte general. $2^{\mathrm{a}}$ ed. Buenos Aires: Hammurabi, 2012. . La posición de garante en el ejercicio de funciones de vigilancia en el ámbito empresarial. In Curso de derecho penal económico. Madrid: Marcial Pons, 1998.

. Sobre el concurso de delito fiscal y blanqueo de dinero. Cizur Menor: Aranzadi, 2012.

BADARÓ, Gustavo Henrique. Juiz natural no processo penal. São Paulo: RT, 2014.

BADARÓ, Gustavo Henrique; BOTTINI, Pierpaolo Cruz. Lavagem de dinheiro: aspectos penais e processuais penais: comentários à Lei 9.613/1998, com as alterações da Lei 12.683/2012. $3^{\mathrm{a}}$ ed. São Paulo: RT, 2016.

BADARÓ, Jennifer Cristina Ariadne Falk. Lavagem de dinheiro e evasão de divisas: análise das hipóteses de concurso de crimes e de concurso aparente de normas. Monografia apresentada para obtenção do título de Especialista no Curso de Pós-Graduação Lato Sensu, Especialização em Direito Penal e Direito Processual Penal da Pontifícia Universidade Católica de São Paulo, sob orientação da Professora Eloisa de Sousa Arruda, 2010. 
BADARÓ, Jennifer Cristina Ariadne Falk. Lavagem de dinheiro: estudo crítico da tipificação da modalidade culposa. In Direito penal econômico: questões atuais. São Paulo: RT, 2011.

BAIGÚN, David. Los delitos de peligro y la prueba del dolo. Montevideo: Julio César Faira, 2007.

BAJO FERNANDEZ, Miguel. El destinado delito de blanqueo de capitales. In Política Criminal y Blanqueo de Capitales. BAJO FERNANDEZ, Miguel; BACIGALUPO, Silvina (org.). Madrid: Marcial Pons, 2009.

BAJO FERNANDEZ, Miguel; BACIGALUPO, Silvina. Derecho Penal Económico. Madrid: Centro de Estudios Ramón Areces, 2001.

BARRETO, Tobias. Prolegômenos do Estudo do Direito Criminal. In Estudos de direito II. Rio de Janeiro, Ed. Diário Oficial, 2012.

BARROS, Marco Antonio de. Lavagem de capitais e obrigações civis correlatas. $4^{\mathrm{a}}$ ed. São Paulo: RT, 2013.

BARROS, Marco Antonio de; SILVA, Thiago Minetti Apostólico. Lavagem de ativos: dolo direto e a inaplicabilidade da teoria da cegueira deliberada. Revista dos Tribunais. v. 957, 2015, p. 203-256.

BAUMANN, Jürgen. Casos penales y soluciones. Parte general. Buenos Aires: Pannedille, 1971.

BECHARA, Ana Elisa Liberatore Silva. Bem Jurídico-Penal. São Paulo: Quartier Latin, 2014.

. Critérios político-criminais da intervenção penal no âmbito econômico: uma lógica equivocada. In Direito penal econômico: questões atuais. São Paulo: RT, 2011.

BECK, Francis Rafael. A doutrina da cegueira deliberada e sua (in)aplicabilidade ao crime de lavagem de dinheiro. Revista de Estudos Criminais. n. 41, v. 10, 2011, p. 45-68.

BITENCOURT, Cesar Roberto; BREDA, Juliano. Crimes contra o sistema financeiro nacional \& contra o mercado de capitais. Rio de Janeiro: Lumen Juris, 2010.

BITENCOURT, Cezar Roberto. Código penal comentado. $4^{\mathrm{a}}$ ed. São Paulo: Saraiva, 2007. . Tratado de Direito Penal. Parte geral 1. 16ª ed. São Paulo: Saraiva, 2011. 
BIVAR, Artur. Dicionário Geral e Analógico da Língua Portuguesa. t. III. Porto: Edições Ouro, [s.d].

BLANCO CORDERO, Isidoro. Eficacia del sistema de prevención del blanqueo de capitales. Estudio del cumplimiento normativo (compliance) desde una perspectiva criminológica. Eguzkilore. $n^{\circ} 23$. San Sebastián: Instituto Vasco de Criminología, 2009.

. El delito de blanqueo de capitales. $2^{\text {a }}$ ed. Cizur Menor: Aranzadi, 2002.

- Responsabilidad penal de los empleados de banca por el blanqueo de capitales. Estudio particular de la omisión de la comunicación de las operaciones sospechosas de estar vinculadas al blanqueo de capitales. Granada: Editorial Comares, 1999.

BOCK, Denis. Compliance y deberes de vigilância em la empresa. Trad. Ivó Coca Vila. In Compliance y teoria del Derecho Penal. Eds. Lothar Kuhlen; Juan Pablo Montiel; Íñigo Ortiz de Urbina Gimeno. Madrid: Marcial Pons, 2013.

BoCKElmanN, Paul; VOLK, Klaus. Direito Penal. Parte geral. Trad. Gercélia Batista de Oliveira Mendes. Belo Horizonte: DelRey, 2007.

BONFIM, Márcia Monassi Mougenot; BONFIM, Edilson Mougenot. Lavagem de dinheiro. $2^{\mathrm{a}}$ ed. São Paulo: Malheiros, 2008.

BOTTINI, Pierpaolo Cruz. Do tratamento penal da ingerência. Tese de Livre Docência apresentada ao Departamento de Direito Penal, Medicina Forense e Criminologia da Faculdade de Direito da Universidade de São Paulo. São Paulo, 2015.

. Prevenção à lavagem de dinheiro: novas perspectivas sob o prisma da lei e da jurisprudência. Revista do Direito Bancário e do Mercado de Capitais. v. 67, 2015, p. 163-195.

. Da omissão penalmente relevante. In BADARÓ, Gustavo Henrique; BOTTINI, Pierpaolo Cruz. Lavagem de dinheiro: aspectos penais e processuais penais: comentários à Lei 9.613/1998, com as alterações da Lei 12.683/2012. $3^{\text {a }}$ ed. São Paulo: RT, 2016.

. Dos tipos penais. In BADARÓ, Gustavo Henrique; BOTTINI, Pierpaolo Cruz. Lavagem de dinheiro: aspectos penais e processuais penais: comentários à Lei 9.613/1998, com as alterações da Lei 12.683/2012. $3^{\text {a }}$ ed. São Paulo: RT, 2016. 
BOTTINI, Pierpaolo Cruz. Lavagem de dinheiro na APN 470/MG. Revista dos Tribunais. v. 933, 2013. P. 383.

. O crime de lavagem de dinheiro. In BADARÓ, Gustavo Henrique; BOTTINI, Pierpaolo Cruz. Lavagem de dinheiro: aspectos penais e processuais penais: comentários à Lei 9.613/1998, com as alterações da Lei 12.683/2012. $3^{\mathrm{a}}$ ed. São Paulo: RT, 2016.

. Políticas de combate à lavagem de dinheiro. In BADARÓ, Gustavo Henrique; BOTTINI, Pierpaolo Cruz. Lavagem de dinheiro: aspectos penais e processuais penais: comentários à Lei 9.613/1998, com as alterações da Lei 12.683/2012. $3^{\mathrm{a}}$ ed. São Paulo: RT, 2016.

. Programas de compliance voltados à prevenção da lavagem de dinheiro. In BADARÓ, Gustavo Henrique; BOTTINI, Pierpaolo Cruz. Lavagem de dinheiro: aspectos penais e processuais penais: comentários à Lei 9.613/1998, com as alterações da Lei 12.683/2012. $3^{\mathrm{a}}$ ed. São Paulo: RT, 2016.

BOTTKE, Wilfired. Mercado, criminalidad organizada y blanqueo de dinero en Alemania. In Revista Penal. ${ }^{\circ}$ 2. Barcelona: La Ley, 1998.

BRANDÃO, Cláudio. Teoria jurídica do crime. Rio de Janeiro: Forense, 2001.

BRANDÃO, Nuno. Branqueamento de capitais: o sistema comunitário de prevenção. Coimbra: Coimbra, 2002.

BRUNO, Aníbal. Direito Penal. Parte Geral. Tomo II, $3^{\mathrm{a}}$ ed. Rio de Janeiro: Forense, 1967.

BUENO, Francisco da Silveira. Grande Dicionário Etimológico Prosódico da Língua Portugesa. São Paulo: Saraiva, n. 6, 1966.

BUSTOS RAMÍREZ, Juan J.; HORMAZÁBAL MALARÉE, Hernán. Lecciones de derecho penal. Parte General. Madrid: Trotta, 2006.

BUSTOS RAMÍREZ, Juan. Introducción al derecho penal. 3 ed. Bogotá: Temis, 2005.

CADENAS CORTINA, Cristina. Problemas de la penalidade en los delitos de receptación y blanqueo de dinero. In Cuadernos de Política Criminal. n ${ }^{\circ} 56$. Madrid: EDERSA, 1995. 
CALLEGARI, André Luís. Lavagem de dinheiro: aspectos penais da lei n 9.613/98. $2^{\mathrm{a}}$ ed. Porto Alegre: Livraria do Advogado, 2008.

- Participação (punível?) de agentes financeiros no delito de lavagem de dinheiro. Revista Brasileira de Ciências Criminais. v. 44, 2003, p. 198-211.

CAMARGO, Antonio Luís Chaves. Imputação Objetiva e Direito Penal Brasileiro. São Paulo: Livraria Paulista, 2002.

. Tipo penal e linguagem. Rio de Janeiro: Forense, 1982.

CARDOSO, Débora Motta. A lavagem de dinheiro culposa frente aos excessos punitivos. Estudos em homenagem a Vicente Greco Filho. Coord. Renato de Mello Jorge Silveira; João Daniel Rassi. São Paulo: LiberArs, 2014.

. Criminal compliance na perspectiva da lei de lavagem de dinheiro. São Paulo: LiberArs, 2015.

CARLI, Carla Veríssimo de. Lavagem de Dinheiro. Ideologia da criminalização e Análise do discurso. $2^{\mathrm{a}}$ ed. Porto Alegre: Verbo Jurídico, 2012.

- Sistema internacional antilavagem de dinheiro. In Lavagem de Dinheiro: prevenção e controle penal. Coord. Carla Veríssimo de Carli. $2^{\mathrm{a}}$ ed. Porto Alegre: Verbo Jurídico, 2013.

CARO CORIA, Dino Carlos. Sobre el tipo básico de lavado de activos. In Anuario de derecho penal económico y de la empresa. Lima: CEDPE: 2012.

CARPIO DELGADO, Juana Del. El delito de blanqueo de bienes en el nuevo codigo penal. Valencia: Tirant to blanch, 1997.

CARRARA, Franceso. Programa do Curso de Direito Criminal. Parte Geral. Trad. José Luiz V. de A. Franceschini; J. R. Prestes Barra. v. 1. São Paulo: Saraiva, 1956.

CASTELLAR, João Carlos. Lavagem de dinheiro. A questão do bem jurídico. Rio de Janeiro: Revan, 2004.

CASTILHO, Ela Wiecko Volkmer de. O controle penal nos crimes contra o sistema financeiro nacional. Lei n. 7.492, de 16/6/86. $1^{\text {a }}$ ed. $2^{\text {a }}$ Tiragem. Belo Horizonte: Del Rey, 2001.

CASTRO MORENO, Abraham. Consideraciones críticas sobre la aplicación e interpretación del tipo subjetivo de los delitos de blanqueo de capitales. Libro homenaje al prof. Luis Rodríguez Ramos. Coord. Francisco Javier Álvarez García, Miguel Angel Cobos Gómez de Linares, Pilar Gómez Pavón, Araceli 
Manjón-Cabeza Olmeda, Amparo Martínez Guerra. Valencia: Tirant lo Blanch, 2013.

CERVINI, Raúl. Os processos de descriminalização. $2^{\text {a }}$ ed. São Paulo: RT, 2002.

COBO DEL ROSAL, Manoel. El blanqueo de capitales y suprevención. In Quisicosas de los delitos y de las penas. Madrid: CESEJ, 2005.

. La recepción de las normas de la Comunidad Europea en la legislación penal contra el blanqueo de capitales. Cuadernos de Política Criminal. Segunda Época. $n^{\circ}$ 85. Madrid: CESEJ, 2005.

COBO DEL ROSAL, Manoel; ZABALA LÓPEZ-GOMEZ, Carlos. Blanqueo de capitales. Abogados, procuradores, y notarios, inversores, bancarios y empresarios. (Repercusión en las leyes españolas de lãs nuevas directivas de La Comunidad Europea). Madrid: CESEJ, 2005.

COELHO, Inocêncio Mártires. Fundamentos do estado de direito. In MENDES, Gilmar Ferreira; COELHO, Inocêncio Mártires; BRANCO, Paulo Gustavo Gonet. Curso de Direito Constitucional. 5a ed. São Paulo: Saraiva, 2010.

CORCOY BIDASOLO, Mirentxu. EI delito imprudente. Criterios de imputación del resultado. $2^{\mathrm{a}}$ ed. Buenos Aires: B de F, 2005.

COSTA E SILVA, Antonio José. Código Penal dos Estados Unidos do Brasil, São Paulo: Companhia Ed. Nacional, v. I, 1930.

COSTA JR., Paulo José da. Comentários ao Código Penal. v. I. São Paulo: Saraiva, 1986.

COSTA JR., Paulo José da; QUEIJO, Maria Elizabeth; MACHADO, Charles M. Crimes do colarinho branco. São Paulo: Saraiva, 2000.

COSTA, Gerson Godinho. O tipo objetivo da lavagem de dinheiro. In Lavagem de dinheiro. Comentários à lei pelos juízes das varas especializadas em homenagem ao Ministro Gilson Dipp. BALTAZAR JUNIOR, José Paulo; MORO, Sergio Fernando (org.). Porto Alegre: Livraria do Advogado, 2007.

D'AVILA, Baio Roberto. Ofensividade e crimes omissivos próprios. Contributo à compreensão do crime como ofensa ao bem jurídico. Coimbra: Coimbra, 2005.

DÍAZ PITA, Maria del Mar. EI dolo eventual. Valencia: Tirant lo blanch, 1994. - La presunta inexistencia del elemento volitivo y su imposibilidad de normativización. Revista Penal. n. 17, 2006, p. 59-71. 
DÍAZ-MAROTO Y VILLARELO, Julio. Algunas notas sobre el delito de blanqueo de capitales. In Revista de Derecho Penal y Criminología. Madrid: Marcial Pons, 2000.

. Recepción de las propuestas del GAFI y de las directivas europeas sobre el blanqueo de capitales en el derecho español. In BAJO FERNANDEZ, Miguel; BACIGAlUPO, Silvina (org.). Política Criminal y Blanqueo de Capitales. Madrid: Marcial Pons, 2009.

DÍEZ RIPOLLÉS, José Luis. El Blanqueo de Capitales Procedentes del Trafico de Drogas. La recepción de lalegislación internacional em el ordenamiento penal español. Actualidad Penal. n 32/5. Madrid: Actualidad, 1994.

. Los elementos subjetivos del delito. Bases metodológicas. $2^{\mathrm{a}}$ ed. Montevideo: Julio César Faira, 2007.

DOPICO GÓMEZ-ALLER, Jacobo. Posición de garante del compliance officer por infracción del 'deber de control': uma aproximación tópica. In El Derecho Penal Económico en la era Compliance. Direc. Luis Arryo Zapatero; Adán Nieto Martín. Valencia: Tirant lo blanch, 2013.

DOTTI, René Ariel. Curso de Direito Penal. Parte Geral. $5^{\text {a }}$ ed. São Paulo: RT, 2013.

FABIÁN CAPARRÓS, Eduardo A. Algunas observaciones sobre el blanqueo imprudente de capitales (aspectos doctrinales y jurisprudenciales). Revista Brasileira de Ciências Criminais. v. 89. Mar-Abr/2011. p. 131-158.

. El delito de blanqueo de capitales. In EI sistema penal frente a los retos de la nueva sociedad. Madrid: Colex, 2003.

. El delito de blanqueo de capitales. Madrid: Colex, 1998.

FARALDO CABANA, Patricia. Aspectos básicos del delito de blanqueo de bienes en el código penal de 1995. Estúdios Penales y Criminológicos. $n^{\circ}$ XXI. Santiago de Compostela: Universidad de Santiago de Compostela. Servicio de Publicaciones, 1998.

- La regulación del comisso en España. Especial referencia a los comisos específicos enlos delitos de tráfico de drogas, blanqueo de bienes y contrabando. Revista Peruana de Ciencias Penales. $n^{\circ}$ 20. Lima: IDEMSA, 2008. - Los autores del delito de blanqueo de bienesenel Código Penal Español de 1005. Especial alusión a los proveedores de bienes y/o servicios: el caso de los 
Abogados y Asesores Fiscales. Anuário de Derecho Penal y Ciencias Penales. Tomo LIX. Madrid: Ministério de Justicia, 2008.

FARIA, Antonio Bento de. Annotaçoes Theorico-Praticas ao Codigo Penal do Brazil. Rio de Janeiro: Papelaria União, 1904.

FEIJOO SANCHEZ, Bernardo. EI dolo eventual. Bogotá: Universidad Externado de Colombia, 2002.

. Imputación objetiva en el Derecho penal económico y empresarial. Esbozo de una teoría general de los delitos económicos. Indrect. Barcelona, 2009, p. 1-74.

. La distinción entre dolo e imprudencia en los delitos de resultado lesivo. Sobre la normativización del dolo. Cuadernos de política criminal. n. 65, 1998, p. 269-364.

. La teoria de la ignorancia deliberada en Derecho penal: una peligrosa doctrina jurisprudencial. InDrect, n. 3, 2015.

. Mejor no saber...más. Discusiones. n. XIII, 2013, p. 101-137.

FERRÉ OLIVÉ, Juan Carlos. "Blanqueo" de capitales y criminalidad organizada. In Nuevas tendências del derecho penal econômico y de la empresa. REYNA ALFARO, Luis Miguel (coord.). Lima: ARA, 2005.

FERREIRA, Gilberto. Aplicação da pena. Rio de Janeiro: Forense, 1995.

FIANDACA, Giovanni. Sul dolo eventuale nella giurisprudenza più recente, tra approccio oggettivizzante-probatorio e messaggio generalpreventivo. Osservazioni in margine a Corte d'Assise di Tprino, 15 aprile 2011 (dep. 14 novembre 2011), Pres. Iannibelli, Est. Dezani, imp. Espenhahn e altri. Diritto Penale Contemporaneo, n. 1, 2012, p. 152-162.

FRAGOSO, Heleno Cláudio. Lições de Direito Penal. Parte Geral. 4 ${ }^{\mathrm{a}}$ ed. Rio de Janeiro: Forense, 1980.

FRANCO, Alberto Silva. Código Penal e sua interpretação. Doutrina e Jurisprudência. Coord. Alberto Silva Franco; Rui Stoco. $8^{\mathrm{a}}$ ed., São Paulo: RT, 2007.

. Crime doloso e crime culposo. In FRANCO, Alberto Silva; STOCO, Rui (coord.). Código penal e sua interpretação. Doutrina e Jurisprudência. $8^{\mathrm{a}}$ ed. São Paulo: RT, 2007.

FRANK, Reinhard. Sobre la estructura del concepto de culpabilidad. Trad. Gustavo Eduardo Aboso; Tea Löw. Buenos Aires: Julio Cèsar Faria, 2004. 
FREIRE, Laudelino. Grande e Novíssimo Dicionário da Língua Portuguesa. v. IV. Rio de Janeiro: A noite, 1943.

FRISCH, Wolfgang. Comportamiento típico e imputación del resultado. Trad. Joaquín Cuello Contreras; José Luis Serrano González de Murillo. Barcelona: Marcial Pons, 2004.

GARCÍA CAVERO, Percy. Criminal compliance. Lima: Palestra, 2014.

GARCIA, Basileu. Instituições de Direito Penal. Tomo I, $2^{\text {a }}$ ed. São Paulo: Max Limonad, 1954.

GIMERNAT ORDEIG, Enrique. El delito de omisión impropia. Revista de derecho penal y criminologia. N. 4, 1999, p. 525-554.

. Omisión impropia e incremento del riesgo em el Derecho penal de empresa.

Anuario de derecho penal y ciencias penales. Tomo 54, n. 1, 2001, p. 5-26.

GÓMEZ DE LA TORRE, Ignacio Berdugo; FABIÁN CAPARRÓS, Eduardo A.. La 'emancipación' del delito de blanqueo de capitales en el derecho penal español. In Revista Brasileira de Ciências Criminais. v. 87, Nov-Dez/2010. p. 57-83.

GÓMEZ INIESTA, Diego J. EI delito de blanqueo de capitales en derecho español. Barcelona: Cedecs, 1996.

GRECO FILHO, Vicente. Tipicidade, bem jurídico e lavagem de valores. In Direito

Penal Especial, Processo Penal e Direitos Fundamentais. Visão LusoBrasileira. Coord. José de Faria Costa; Marco Antonio Marques da Silva. São Paulo: Quartier Latin, 2006.

GRECO, Luís. Algumas observações introdutórias à "Distinção entre dolo e culpa", de Ingeborg Puppe. In PUPPE, Ingeborg. A distinção entre dolo e culpa. Trad. Luís Greco. Barueri: Manole, 2004, p. IX-XIX.

. Comentario al artículo de Ramon Ragués. Discusiones. n. XIII, 2013, p. 67-77.

. Cumplicidade através de ações neutras. A imputação objetiva na participação. Rio de Janeiro: Renovar, 2004.

. Dolo sem vontade. In Liber Amicorum de José de Sousa e Brito, em comemoração ao $70^{\circ}$ Aniversáio. Org. João Lopes Alves [et al.]. Coimbra: Almedina, 2009.

. Princípios Fundamentais e Tipo no Novo Projeto de Código Penal (Projeto de Lei $n^{\circ}$ 236/2012 do Senado Federal. In Reforma Penal. A crítica científica à 
Parte Geral do Projeto de Código Penal (PLS 236/2012). Alaor Leite (Org.) São Paulo: Atlas, 2015.

GRECO, Luís; LEITE, Alaor. O que é e o que não é na teoria do domínio do fato sobre a distinção entre autor e partícipe no direito penal. In Revista dos Tribunais. v. 933/2013, jul. 2013, p. 61.

GRECO, Luís; LEITE, Alaor; TEIXEIRA, Adriano; ASSIS, Augusto. Autoria como domínio do fato. Estudos introdutórios sobre o concurso de pessoas no direito penal brasileiro. São Paulo: Marcial Pons, 2014.

HASSEMER, Winfried. ¿Puede haber delitos que no afecten a un bien jurídico penal? In HEFENDEHL, Roland (Ed.). La teoria del bien jurídico. ¿Fundamento de legitimación del Derecho penal o juego de abalorios dogmático? Madrid: Marcial Pons, 2007.

. Introdução aos fundamentos do Direito Penal. Trad. Pablo Rodrigo Alflen da Silva. Porto Alegre: Sergio Antonio Fabris, 2005.

HASSEMER, Winfried. Los elementos característicos del dolo. Trad. Maria del Mar Díaz Pita. Anuario de derecho penal y ciencias penales. Tomo 43, n. 1, 1990, p. 909-932.

HOUAISS, Antonio; VILLAR, Mauro de Salles; FRANCO, Francisco Manoel de Mello. Dicionário Houaiss da Língua Portuguesa. Rio de Janeiro, 2001.

HRUSCHKA, Joachim. Imputación y derecho penal: estúdios sobre la teoria de la imputación. Trad. Pablo Sánchez-Ostiz. Navarra: Azanzadi, 2005.

. Sobre la difícil prueba del dolo. Trad. Ramon Ragués i Vallès. Imputación y Derecho Penal. $2^{\mathrm{a}}$ ed. Buenos Aires: Euros Editores, 2009.

HUNGRIA, Nelson. Comentários ao Código Penal. v. I, Tomo II. $4^{\mathrm{a}}$ ed. Rio de Janeiro: Forense, 1958.

. Comentários ao Código Penal. v. VII. $3^{\mathrm{a}}$ ed. Rio de Janeiro: Revista Forense, 1967.

J. CÓRDOBA, Fernando J.. Dolo y evitabilidad individual. Revista Pensar em Derecho. v. 1, 2012, p. 213-226.

. Delito de lavado de dinero. Buenos Aires: Hammurabi, 2016. 
JAKOBS, Günther. A imputação objetiva no Direito Penal. Trad. André Luís Callegari. São Paulo: RT, 2000.

. Acción y omisión en derecho penal. Trad. Luis Carlos Rey Sanfiz; Javier Sanchez-Vera. Bogotá: Universidad Externado de Colombia, 2000.

. Derecho Penal. Parte General. Fundamentos y teoría de la imputación. Trad. Joaquin Cuello Contreras; Jose Luis Serrano Gonzalez de Murillo. $2^{\mathrm{a}}$ ed. Madrid: Marcial Pons, 1997.

. Indiferencia como dolo indirecto. Trad. Carlos Pérez del Valle. In Dogmática y

ley penal. Libro homenaje a Enrique Bacigalupo. Tomo I. Madrid: Marcial Pons, 2004.

. La competencia por organización en el delito omissivo. Trad. Enrique Peñaranda Ramos. Bogotá: Universidad Externado de Colombia, 1994.

. La imputación penal de la acción y de la omisión. Trad. Javier Sánchez-Vera Gómez-Trelles. Anuario de derecho penal y ciencias penales. Tomo 49, n. 3, 1996, p. 835-874.

. Sobre el tratamento de las alteraciones volitivas y cognitivas. Trad. Maria del Mar Diaz Pita. Anuario de derecho penal y ciencias penales. Tomo 45, n. 1, 1992, p. 213-234.

. Sobre la función de la parte subjetiva del delito em Derecho Penal. Trad. Joaquín Cuello Contreras. Anuario de derecho penal y ciencias penales. Tomo 42, n. 2, 1989, p. 663-652.

. Sobre la normativización de la dogmática jurídico-penal. Trad. Manuel Cancio Meliá; Bernardo Feijóo Sánchez. Bogotá: Universidad Externado de Colombia, 2004.

- Teoría y práxis de la injerencia. Trad. Manuel Cancio Meliá. Anuario de derecho penal y ciencias penales. Tomo 52, n. 1-3, 1999, p. 17-50.

JESCHECK, Hans-Heinrich. Nueva dogmática penal y política criminal em perspectiva comparada. Trad. Angel Sanz Morán. Anuario de derecho penal y ciencias penales. Tomo 39, n. 1, 1986, p. 9-32.

JESCHECK, Hans-Heinrich; WEIGEND, Thomas. Tratado de Derecho Penal. Parte General. Trad. Miguel Olmedo Cardenete. $5^{\text {a }}$ ed. Granada: Editorial Comares, 2002. 
JIMÉNEZ DE ASÚA, Luis. Tratado de Derecho Penal. Tomo V. La Culpabilidad. $4^{\text {a }}$ ed. Buenos Aires: Editorial Losada, 1950.

JIMÉNEZ GARCÍA, Francisco. La prevención y lucha contra el blanqueo de capitales y la corrupción. Interacciones evolutivas em um Derecho internacional global. Granada: Comares, 2015.

KAUFMANN, Armin. Dogmática de los delitos de omisión. Trad. Joaquín Cuello Contreras; José Luis Serrano González de Murillo. Madrid: Marcial Pons, 2006.

. El dolo eventual en la estructura del delito. Trad. R. F. Suárez Montes. Anuario de derecho penal y ciencias penales. Tomo 13, n. 2, 1960, p. 185206.

KUHLEN, Lothar; MONTIEL, Juan Pablo; URBINA GIMENO, Íñigo Ortiz. (eds.) Compliance y teoria del Derecho penal. Madrid: Marcial Pons, 2013.

LAMPE, Ernst-Joachim. El nuevo tipo penal del blanqueo de dinero ( $\$ 261 \mathrm{StGB}$ ). In Estúdios Penales y Criminológicos. $\mathrm{n}^{\circ}$ XX. Santiago de Compostela: Santiago de Compostela: Universidad de Santiago de Compostela. Servicio de Publicaciones, 1997.

LASCURAÍN SÁNCHEZ, Juan Antonio. Los delitos de omisión: fundamento de los deberes de garantía. Madrid: Civitas, 2002.

LAUFER, Christian. A teoria da cegueira deliberada e o direito penal brasileiro. Boletim IBCCRIM. n. 204, v. 17, 2009. 10-11.

LAURENZO COPELlO, Patricia. Dolo y conocimiento. Valencia: Tiral lo blanch, 1999.

LIMA, Carlos Fernando dos Santos. O sistema nacional antilavagem de dinheiro: as obrigações de compliance. In Lavagem de Dinheiro: prevenção e controle penal. Coord. Carla Veríssimo de Carli. $2^{\text {a }}$ ed. Porto Alegre: Verbo Jurídico, 2013.

MACEDO, Carlos Márcio Rissi. Lavagem de Dinheiro. Curitiba: Juruá, 2008.

MACHADO, Fábio Guedes de Paula. A reconstrução do dolo na teoria do delito. Revista do Ministério Público do Estado de Minas Gerais. v. II, n. 7, out./dez. 2006, p. 11-15. . A tentativa no dolo eventual. In Direito Penal na Pós-Modernidade. Escritos em Homenagem a Antonio Luis Chaves Camargo. Coord. Renato de Mello 
Jorge Silveira; Alamiro Velludo Salvador Netto; Luciano Anderson de Souza. São Paulo: Quartier Latin, 2015, p. 171-196.

MACHADO, Maíra Rocha. Lavagem de Dinheiro e Recuperação de Ativos: Brasil,

Nigéria, Reino Unido e Suíça. São Pulo: Quartier Latin, 2006.

MACHADO, Raul. A Culpa no Direito Penal. 2a ed. São Paulo, 1943.

MAIA, Rodolfo Tigre. Lavagem de dinheiro. $2^{\text {a }}$ ed. São Paulo: Malheiros, 2007.

MANRIQUE, María Laura. ¿Mejor no saber? Algunas consideraciones sobre la atribución de responsabilidad penal en caso de ignorancia. Discusiones. n. XIII, 2013, p. 70-100.

. Reproche al "Dolo como reproche". Revista Pensar em Derecho. v. 2, 2013, p. 387-412.

MARQUES, José Frederico. Tratado de Direito Penal. $2^{\text {a }}$ ed. São Paulo: Saraiva, Tomo II, 1965, p. 196.

MARTÍNEZ-BUJÁN PÉREZ, Carlos. Derecho penal económico y de la empresa.

Parte General. $4^{\text {a }}$ ed. Valencia: Tirant lo blanch, 2014.

. El blanqueo de bienesenel Código Penal Español. In Dogmática Penal del

Tercer Milenio. Libro homenaje a los profesores Eugenio Raúl Zaffaroni y

Klaus Tiedemann. Lima : Ara, 2008.

. El concepto "significativo" de dolo: un concepto volitivo normativo. In

Problemas actuales del derecho penal y de la criminología. Estudios penales en memoria de la Profesora Dra. María del Mar Díaz Pita. Valencia: Tirant lo blanch, 2008, p. 323-367.

MARTÍNEZ-BUJÁN PÉREZ, Carlos. Instrumentos Jurídicos Frente a la Globalización de los Mercados (En el ejemplo del blanqueo de capitales). In ZÚÑIGA RODRÍGUEZ, Laura; MÉNDEZ RODRÍGUEZ, Cristina; DIEGO DIAZSANTOS, Ma Rosário (coord.). El Derecho Penal Ante la Globalización. Madrid: COLEX, 2002.

MARTINS, Luiza Faria. A doutrina da cegueira deliberada na lavagem de dinheiro: aprofundamento dogmático e implicações práticas. Revista de Estudos Criminais. n. 55, Outubro/Dezembro 2014, p. 135-162.

MENDRONI, Marcelo Batlouni. Crimes de Lavagem de Dinheiro. São Paulo: Atlas, 2006. 
MILITELLO, Vincenzo. Iniciativas supranacionales en la lucha contra la criminalidad organizada y elblanqueoenelámbito de lasnuevastecnologías. In ZÚÑIGA RODRÍGUEZ, Laura; MÉNDEZ RODRÍGUEZ, Cristina; DIEGO DIAZSANTOS, $\mathrm{M}^{\mathrm{a}}$ Rosário (coord.). Derecho Penal, Sociedad y NuevasTecnologías. Madrid: COLEX, 2001.

MIR PUIG, Santiago. Conocimiento y voluntad en el dolo. Cuadernos de Derecho Judicial. n. 33, 1994, p. 9-35.

. Introducción a las bases del derecho penal. Concepto y método. $2^{\mathrm{a}}$ ed. Montevideo-Buenos Aires: B de F ltda., 2003.

. Sobre lo objetivo y lo subjetivo em el injusto. Anuario de derecho penal y ciencias penales. Tomo 41, n. 3, 1988, p. 661-684.

MIR PUIG, Santiago; CORCOY BIDASOLO, Mirentxu; GÓMEZ MARTÍN, Víctor. (dir.); HORTAL IBARRA, Juan Carlos; VALIENTE IVAÑEZ, Vicente (corrd.). Responsabilidad de la Empresa y Compliance. Programas de prevención, detección y reacción penal. Madrid: Edisofer S. L., 2014.

MORO, Sergio Fernando. Sobre o elemento subjetivo no crime de lavagem. In BALTAZAR JUNIOR, José Paulo; MORO, Sergio Fernando (org.). Lavagem de Dinheiro. Comentários à lei pelos juízes das varas especializadas em homenagem ao Ministro Gilson Dipp. Porto Alegre: Livraria do Advogado, 2007.

MUÑOZ CONDE, Francisco. Derecho Penal. Parte Especial. $17^{\text {a }}$ ed. Valencia: Tirant to blanch, 2009.

NIETO MARTÍN, Adán; MAROTO CALATAYUd, Manuel. Public Compliance. Prevención de la corrupción em administraciones públicas y partidos políticos. Cuenca: Ediciones de la Universidad de Castilla-La Mancha, 2014.

NIETO MARTÍNS, Adán. Problemas fundamentales del cumplimiento normativo em el derecho penal. In Compliance y teoria del Derecho Penal. Eds. Lothar Kuhlen; Juan Pablo Montiel; Íñigo Ortiz de Urbina Gimeno. Madrid: Marcial Pons, 2013.

NORONHA, Edgard Magalhães Noronha. Direito Penal. v. 1. 23 a ed. São Paulo: Saraiva, 1985.

. Direito Penal. v. 2. $21^{\mathrm{a}}$ ed. São Paulo: Saraiva, 1986.

. Do crime culposo. $2^{\text {a }}$ ed. São Paulo: Saraiva, 1996. 
OLIVEIRA, Ana Carolina Carlos de. A responsabilidade por omissão dos sujeitos sensíveis à lavagem de dinheiro: o dever de informação. Tese de doutorado apresentada à Faculdade de Direito da Universidade de São Paulo, 2016.

OLIVEIRA, William Terra de. Dos crimes e das penas. In CERVINI, Raúl; OLIVEIRA, William Terra de; GOMES, Luiz Flávio Gomes. Lei de Lavagem de Capitais. São Paulo: RT, 1998.

ORTIZ DE URBINA GIMENO, Íñigo. ¿Dolo como reproche? Observaciones sobre método y axiología en la propuesta de abandono de la idea de dolo como estado mental. Revista Pensar em Derecho. v. 2, 2013, p. 357-385.

PASCHOAL, Janaina Conceição. Ingerência indevida. Os crimes comissivos por omissão e o controle pela punição do não fazer. Porto Alegre: Sergio Antonio Fabris Editor, 2011.

. Lei 12.683/12 - Mais um capítulo na ingerência indevida. Estudos em homenagem a Vicente Greco Filho. Coord. Renato de Mello Jorge Silveira; João Daniel Rassi. São Paulo: LiberArs, 2014.

. Constituição, criminalização e direito penal mínimo. São Paulo: RT, 2003.

PÉREZ BARBERÁ, Gabriel. Dolo como reproche objetivo hacia el abandono de la idea de dolo como estado mental. Revista Brasileira de Ciências Criminais. v. 95, 2012, p. 13- 30 .

. Dolo como reproche. Hacia el abandono de la idea de dolo como estado mental. Revista Pensar em Derecho. v. 1, 2012, p. 169-211.

. El dolo eventual. Hacia el abandono de la idea de dolo como estado mental. Buenos Aires: Hammurabi, 2011.

. Réplicas a Fernando Córdoba e Íñigo Ortiz de Urbina. Revista Pensar em Derecho. n. 2, 2013, p. 413-422.

PÉREZ CEPEDA, Ana Isabel; BENITO SÁNCHEZ, Carmen Demelsa. La política criminal internacional contra la corrupción. In Revista Brasileira de Ciências Criminais. v. 89. Mar-Abr/2011. p. 13-62.

PÉREZ MANZANO, Mercedes. El tipo subjetivo en los delitos de receptación y blanqueo de dinero. Cuadernos de derecho judicial. Encubrimiento, la receptación y el blanqueo del dinero. Normativa Comunitaria. Madrid: Consejo General de Poder Judicial, 1994.

PINTO, Edson. Lavagem de Capitais e Paraísos Fiscais. São Paulo: Atlas, 2007. 
PITOMBO, Antonio Sergio de Moraes. Lavagem de dinheiro. São Paulo: RT, 2003.

PODVAL, Roberto. O bem jurídico do delito de lavagem de dinheiro. In Revista Brasileira de Ciências Criminais. São Paulo: RT, ano 6, n. 24, 1998.

POLITOFF LIFSCHITZ, Sergio. Los elementos subjetivos del tipo legal. 2 ed. Montevideo: Julio César Faira, 2008.

PORCIÚNCULA, José Carlos. Lo objetivo y lo subjetivo em el tipo penal. Hacia la exteriorización de lo interno. Barcelona: Atelier, 2012.

PRADO, Luiz Regis. Delito de lavagem de capitais: um estudo introdutório. In Revista dos Tribunais. v. 860/2007. Jun/2007. P. 433-455.

. Direito Penal Econômico. São Paulo: RT, 2004.

. Tratado de direito penal brasileiro. Parte geral. Teoria Jurídica do Delito. v.

2. São Paulo: RT, 2014.

PRADO, Rodrigo Leite. Dos crimes: aspectos subjetivos. In Lavagem de Dinheiro.

Prevenção e Controle Penal. Org. Carla Veríssimo de Carli. $2^{\mathrm{a}}$ ed. Porto Alegre: Verbo Jurídico, 2013.

PUPPE, Ingeborg. A distinção entre Dolo e Culpa. Trad. Luís Grecco. Barueri: Manole, 2004.

. Dolo eventual e culpa consciente. Trad. Luís Greco. Revista Brasileira de Ciências Criminais. v. 58, 2006, p. 114-132.

. Dolo, curso causal, imputação. Trad. Luís Greco. In Estudos em homenagem ao Prof. Doutor Jorge de Figueiredo Dias. v. II. Coimbra: Coimbra, 2009.

. La construcción del delito. Trad. Nuria Pastor Muñoz. In El Derecho penal como ciencia. Método, teoría del delito, tipicidad y justificación. Buenos Aires: Euros, 2014, p. 185-206.

. La distinción entre dolo e imprudencia. Comentario al $§ 15$ del Código Penal alemán. Trad. Marcelo A. Sancinetti. Buenos Aires: Hammurabi, 2010.

. Perspectivas conceptuales del dolo eventual. Trad. Ramón Ragués i Vallès. In El Derecho penal como ciencia. Método, teoría del delito, tipicidad y justificación. Buenos Aires: Euros, 2014, p. 291-316.

PUPPO, Alberto. Comentario a "Mejor no saber: sobre la doctrina...", de Ramon Ragués i Vallès. Discusiones. n. XIII, 2013, p. 39-66. 
RAGUÉS I VALLÈS, Ramon. A modo de contrarréplica: la ignorancia deliberada y su difícil encaje em la teoria dominante de la imputación subjetiva. Discusiones. $n$. XIII, 2013, p. 139-165.

. Caso del cinturón. In Casos que hicieron doctrina en derecho penal. Coord. Pablo Sánchez-Ostiz Gutiérrez. 2a ed. Madrid: La Ley, 2011, p. 193/205.

- Consideraciones sobre la prueba del dolo. Revista Brasileira de Ciências Criminais. v. 69, 2007, p. 129-142.

. De nuevo, el dolo eventual: um enfoque revolucionario para um tema classico.

InDret. Barcelona, jul. 2012.

. El dolo y su prueba em el proceso penal. Barcelona: Jose Maria Bosch Editor, 1999.

. La ignorancia deliberada en Derecho penal. Barcelona: Atelier, 2007.

- La responsabilidad penal del testaferro en delitos cometidos a través de sociedades mercantiles: problemas de imputación subjetiva. In Anuario de derecho penal económico y de la empresa. Lima: CEDPE: 2012.

. Mejor no saber: sobre la doctrina de la ignorancia deliberada en Derecho Penal.

Discusiones. n. XIII, 2013, p. 11-37.

REALE JÚNIOR, Miguel. Parte geral do Código Penal. Nova Interpretação. São Paulo: RT, 1988.

RIOS, Rodrigo Sanches. A política criminal destinada à prevenção e repressão da lavagem de dinheiro: o papel do advogado e suas repercussões. In Direito Penal Econômico: análise Contemporânea. VILARDI, Celso Sanchez; PEREIRA, Flávia Rahal Bresser; DIAS NETO, Theodomiro (coord.). São Paulo: Saraiva, 2009 (Série GV law).

. Direito Penal Econômico. Advocacia e lavagem de dinheiro: questões de dogmática jurídico-penal e de política criminal. São Paulo: Saraiva, 2010.

ROBLES PLANAS, Ricardo; PASTOR MUÑOZ, Nuria. Delitos contra el patromonio (III). In Lecciones de derecho penal. Parte especial. Dir. Jesús-María Silva Sánchez; Coord. Ramon Ragués i Vallès. $4^{\mathrm{a}}$ ed. Barcelona: Atelier, 2015.

ROMEO CASABONA, Carlos Maria. Límites de los delitos de comisión por omisión.

In Omisión e imputación objetiva en derecho penal. Jornadas HispanoAlemanas de Derecho Penal en homenaje al Profesor Calus Roxin con motivo de su investidura como Doctor Honoris Causa por la Universidad Complutense de 
Madrid. Edit. Enrique Gimbernat, Bernd Schünemann, Jürgen Wolter. Madrid: Serviocio de Publicaciones. Facultad de Derecho, 1994.

ROMEO CASABONA, Carlos Maria. Sobre a estrutura monista do dolo: uma visão crítica. Ciências Penais. v. 3, 2005, p. 7-32.

ROXIN, Claus. ¿Es La Protección de Bienes Jurídicos una Finalidad del Derecho Penal? In HEFENDEHL, Roland (Ed.). La teoria del bien jurídico. ¿Fundamento de legitimación del Derecho penal o juego de abalorios dogmático? Madrid: Marcial Pons, 2007.

- Autoría y domínio del hecho em Derecho Penal. Trad. Joaquín Cuello Contreras; José Luis Serrano González de Murillo. 7 ed. Madrid: Marcial Pons, 2000 .

. Causalidad y posición de garante en los delitos de omisión impropia. Trad. Margarita Martínez Escamilla. In Estudios penales em homenaje a Enrique Gimernant. Tomo II. Madrid: Edisofer, 2008, p. 1543-1558.

. Derecho Penal. Parte General. Tomo I. Fundamentos. La estructura de la teoría del delito. Trad. Diego-Manuel Luzón Penã; Miguel Díaz; García Colledo; Javier de Vicente Remesa. Madrid: Civitas, 2006.

. Derecho Penal. Parte General. Tomo II. Especiales formas de aparición del delito. Trad. Diego-Manuel Luzón Penã; Miguel Díaz; García Colledo; Javier de Vicente Remesa. Madrid: Civitas, 2014.

. Funcionalismo e imputação objetiva no direito penal. Trad. Luís Greco. Rio de Janeiro: Renovar, 2002.

. Teoria del Tipo Penal. Tipos abiertos y elementos del deber jurídico. Trad. Enrique Bacigalupo. Buenos Aires: Depalma, 1979.

SALVADOR NETTO, Alamiro Velludo. Elementos subjetivos do tipo: teorias do dolo e da culpa. In Direito Penal na Pós-Modernidade. Escritos em Homenagem a Antonio Luis Chaves Camargo. Coord. Renato de Mello Jorge Silveira; Alamiro Velludo Salvador Netto; Luciano Anderson de Souza. São Paulo: Quartier Latin, 2015, p. 39-53.

SALVADOR NETTO, Alamiro Velludo; COSTA, Helena Regina Lobo da; SARCEDO, Leandro. Lavagem de dinheiro no direito penal brasileiro: reflexões necessárias. Boletim IBCCRIM. Ano 21, n. 250, setembro, 2013. 
SANCTIS, Fausto Martin de. Combate à Lavagem de Dinheiro. Teoria e Prática. Campinas: Millennium, 2008.

SANTANA, Selma Pereira. A Culpa Temerária. Contributo para uma construção no direito penal brasileiro. São Paulo: RT, 2005.

SANTOS, Juarez Cirino dos. Direito Penal. Parte Geral. $7^{\text {a }}$ ed. Florianópolis: Empório do Direito, 2017.

. A Reforma Penal: Crítica da Disciplina legal do Crime. In Reforma Penal. A crítica científica à Parte Geral do Projeto de Código Penal (PLS 236/2012). Alaor Leite (Org.) São Paulo: Atlas, 2015.

SATULA, Benja. Branqueamento de capitais. Lisboa: Universidade Católica, 2010.

SCHIMIDT, Andrei Zenkner. Direito Penal Econômico. Parte Geral. Porto Alegre: Livraria do Advogado, 2015.

SCHÜNEMANN, Bernd. De un concepto filológico a un concepto tipológico del dolo. Trad. Mariana Sacher; Carlos Suárez González. Obras. Santa Fe: RubinzalCulzoni, 2009, p. 417-436.

. Do conceito filológico ao conceito tipológico de dolo. Trad. Luís Greco; Ana

Cláudia Grossi. Estudos de direito penal, direito processual penal e filosofia do direito. São Paulo: Marcial Pons, 2013, p. 127-141.

. El llamado delito de omisión impropia o la comisión por omisión. Trad. Beatriz Escudero García-Calderón. In Estudios penales em homenaje a Enrique Gimernant. Tomo II. Madrid: Edisofer, 2008, p. 1609-1630.

. Fundamento y límites de los delitos de omisión impropia. Trad. Joaquín Cuello Contreras; José Luis Serrano Gonzáles de Murillo. Madrid: Marcial Pons, 2009.

. Responsabilidad penal en el marco de la empresa: dificultades relativas a la individualización de la imputación. Trad. Beatriz Spínola Tártalo. Anuario de derecho penal y ciencias penales. Tomo 55, n. 1, 2002, p. 9-38.

SEQUEROS SAZATORNIL, Fernando; DOLZ LAGO, Dr. Manuel-Jesús. Delitos societários y conductas afines. La responsabilidade penal y civil de la sociedade, sus sócios y administradores. 3 ed. Madrid: La ley, 2013. 
SHECAIRA, Sérgio Salomão. Ainda a expansão do direito penal: o papel do dolo eventual. Revista Brasileira de Ciências Criminais. v. 64, 2007, p. 222. . Dolo eventual e culpa consciente. Revista Brasileira de Ciências Criminais. v. 38, 2002, p. 142-153.

SILVA SÁNCHEZ, Jesús María. Fundamentos del Derecho penal de la Empresa. Madrid: Edisofer S. L., 2013.

. Deberes de vigilancia y compliance empresarial. In Compliance y teoria del Derecho Penal. Eds. Lothar Kuhlen; Juan Pablo Montiel; Íñigo Ortiz de Urbina Gimeno. Madrid: Marcial Pons, 2013.

. Teoría del delito y derecho penal económico. Revista Brasileira de Ciências Criminais. v. 99, 2012, p. 327.

SILVA, César Antonio da. Lavagem de dinheiro. Uma nova perspectiva Penal. Porto Alegre: Livraria do Advogado, 2001.

SILVEIRA, Renato de Mello Jorge. A aplicação da teoria da cegueira deliberada nos julgamentos da Operação Lava Jato. Revista Brasileira de Ciências Criminais. v. 122, 2016, p. 255-280.

. A teoria do delito e o enigma do dolo eventual: considerações sobre a aparente nova resposta italiana. Revista Brasileira de Ciências Criminais. v. 121, 2016, p. 223-250.

. Avaliação sobre a responsabilidade criminal do empresário: o caso do incêndio da boate e situações correlatas. In Direito Penal na Pós-Modernidade. Escritos em Homenagem a Antonio Luis Chaves Camargo. Coord. Renato de Mello Jorge Silveira; Alamiro Velludo Salvador Netto; Luciano Anderson de Souza. São Paulo: Quartier Latin, 2015, p. 421-451.

. Cegueira deliberada e lavagem de dinheiro. Boletim IBCCRIM, n. 246, 2013, p. 3-4.

. Compliance, direito penal e lei anticorrupção. São Paulo: Saraiva, 2015.

. Direito Penal Econômico como Direito Penal de Perigo. São Paulo: RT, 2006.

. Direito Penal Empresarial: a omissão do empresário como crime. Belo Horizonte: D’Plácido, 2016. 
SILVEIRA, Renato de Mello Jorge; ORTIZ, Mariana Tranchesi. A particular imputação penal do agente financeiro nos crimes de lavagem de dinheiro. Revista de Direito Bancário e do Mercado de Capitais. v. 54, 2011, p. 231.

SILVEIRA, Renato de Mello Jorge; SAAD-DINIZ, Eduardo. A noção penal dos programas de compliance e as instituições financeiras na 'nova lei de lavagem' lei 12.683/2012. Revista de Direito Bancário e do Mercado de Capitais. v. 57. Jul-Set/2012. p. 267-279. ;; . Compliance, direito penal e lei anticorrupção. São Paulo: Saraiva, 2015.

; _ C C C C C C cooperiminal ção normativa quanto à lavagem de dinheiro. Revista de Direito Bancário e do Mercado de Capitais. v. 56. Abr/2012. p. 293.

SIQUEIRA, Galdino. Direito Penal Brazileiro. Rio de Janeiro: Jacintho Ribeiro dos Santos Ed., 1921.

SOUZA, Braz Florentino Henriques de. Lições de Direito Criminal. $2^{\text {a }}$ ed. Paris, J. P. Aillaud Guillard e C., 1872.

StRatenWERTH, Günter. Derecho Penal. Parte General, I. Trad. Gladys Romero. Madrid: Editoriales Derechos Reunidas, 1982.

SUÁREZ GONZÁLEZ, Carlos J. Blanqueo de capitales y merecimiento de pena: consideraciones críticas a la luz de lalegislación española. Cuadernos de Política Criminal. ${ }^{\circ}$ 58. Madrid: EDERSA, 1996.

SYDOW, Spencer Toth. A Teoria da cegueira deliberada. Belo Horizonte: D’Plácido, 2017.

TASSI, Sauro. Il dolo. Milani: CEDAM, 1992.

TAVARES, Juarez. Alguns aspectos da estrutura dos crimes omissivos. Revista Brasileira de Ciências Criminais. v. 15, 91996, p. 125-157.

. As controvérsias em torno dos crimes omissivos. Rio de Janeiro: Instituto Latino-Americano de Cooperação Penal, 1996.

. Espécies de dolo e outros elementos subjetivos do tipo. Revista da Faculdade de Direito UFPR. v. 14, n. 0, 1971, p. 107-119.

. Teoria dos crimes omissivos. São Paulo: Marcial Pons, 2012.

. Teorias do delito: variações e tendências. São Paulo: RT, 1980. 
TAVARES, Juarez. Projeto de Código Penal. A Reforma da Parte Geral. In Reforma Penal. A crítica científica à Parte Geral do Projeto de Código Penal (PLS 236/2012). Alaor Leite (Org.) São Paulo: Atlas, 2015, p. 67.

TIEDEMANN, Klaus. Manual de derecho penal económico. Parte general y especial.

Trad. Coord. Manuel A. Abanto Vásquez. Valencia: Tirant lo blanch, 2010.

TOLEDO, Francisco de Assis. Princípios básicos de direito penal. De acordo com a Lei n. 7.209, de 11-7-1984, e a Constituição de 1988. 4 ed. São Paulo: Saraiva, 1991.

. O erro no Direito Penal. São Paulo: Saraiva, 1977.

VALENZUELA S., Jonatan. Introducción: "Mejor no saber sobre la doctrina de la ignorancia deliberada en Derecho Penal”. Discusiones. n. XIII, 2013, p. 5-8.

VELO, Joe Tennyson. A fenomenologia do dolo eventual. In Revista Brasileira de Ciências Criminais, v. 108/2014, p. 15.

VIANNA, Paulo Domingues. Direito Criminal. Segundo as preleções Professadas pelo

Dr. Lima Drummond na Faculdade Livre de Sciencias Juridicas e Sociaes do Rio de Janeiro. $6^{\text {a }}$ ed. Rio de Janeiro: Briguiet e Cia Ed., 1936.

VIDALES RODRIGUEZ, Caty. Los delitos de receptación y legitimación de Capitalesenel Código Penal de 1995. Valencia: Tirant lo Blanch, 1997.

VILARDI, Celso Sanchez. O crime de lavagem de dinheiro e o início de sua execução.

Revista Brasileira de Ciências Criminais. v. 47, 2004, p. 11-30.

VIVES ANTÓN, Tomás S. Fundamentos del sistema penal. $2^{\mathrm{a}}$ ed. Valencia: Tirant lo blanch, 2011.

. Reexamen del dolo. In Problemas actuales del derecho penal y de la criminologia. Estudios penales em memoria de la Professora Dra. María del Mar Díaz Pita. Valencia: Tirant lo blanch, 2008, p.369-388.

VOLK, Klaus. Indtroduzione al dirito penale tedesco. Parte generale. Padova: Cedam, 1993.

VON LISZT, Franz. Tratado de Direito Penal Alemão. Tomo I. Trad. José Hygino Duarte Pereira. Rio de Janeiro: F. Briguet \& C., 1899.

WELZEL, Hans. Derecho Penal Aleman. Parte General. Trad. Juan Bustos Ramírez; Sergio Yáñez Pérez. $3^{\text {a }}$ ed. Santiago: Editorial Juridica de Chile, 1987.

. El nuevo sistema del derecho penal. Una introducción a la doctrina de la acción finalista. Buenos Aires: Euros Editores, 2004. 
WESSELS, Johannes. Direito Penal. Parte Geral. Trad. Juarez Tavares. Porto Alegre: Fabris, 1976.

ZAFFARONI, Eugenio Raul; BATISTA, Nilo; ALAGIA, Alejandro; SLOKAR, Alejandro. Direito Penal Brasileiro: teoria do delito: introdução histórica e metodológica, ação e tipicidade. v. 2. Tomo I, Rio de Janeiro: Revan, 2010.

ZARAGOZA AGUADO, Javier Alberto. Análisis substantivo del delito (II): cuestiones de interés sobre el delito de blanqueo de bienes de origen criminal: la prueba indiciaria, la comisión culposa, nuevas orientaciones en derecho comparado. In Prevención y Represión del Blanqueo de Capitales. Madrid: Consejo General del Poder Judicial, 2000. . El blanqueo de capitales y la receptación. In Delitos y Cuestiones Penales em el Ámbito Empresarial. Madrid: Expansión/Garrigues e Andersen, 1999. . La respuesta economica al trafico ilegal de drogas: el delito de blanqueo, el comiso y la intervension de la carga de la prueba. In Estúdios del Ministerio Fiscal. Curso de formacion. Madrid: Ministerio de Justicia e Interior. Secretaria General Tecnica, 1995.

ZIELINSKI, Diethart. Dolo e imprudencia. Comentario a los $\S \S 15$ y 16 del Código Penal alemán. Trad. Marcelo A. Sancinetti. Buenos Aires: Hamurabi, 2003. Orig. 1990. 